It is, however, interesting and encouraging to read Dr. Stevenson's essay, which exhibits all the care and precision of the trained scientific observer, combined with the open and unprejudiced outlook of the philosopher. His thesis is worthy of that profound thinker, William James, in honour of whose memory this essay was composed. We congratulate the author on his approach to this difficult subject, and we recommend this booklet to all who are seriously interested in it.

\section{Neurovascular Compression Syndromes of the Shoulder Girdle}

L. M. Rosati, M.D., and J. W. LoRD, M.D. Pp. vi + 168, illustrated. New York and London: Grune \& Stratton, 1960. $\$ 7.25$.

- This monograph deals with a rather confusing group of clinical problems which are of interest to neurologists and surgeons alike. The authors have divided the work into 14 short chapters. Particular facets of the problems under discussion can be quickly located but this has led to repetitions in the text which does not read smoothly.

The description of diagnostic clinical tests is supplemented with excellent drawings by Frank Netter, M.D. Throughout the work, references to the literature are integrated in such a way that the reader is provided with a clear picture of the evolution of thoughts on the etiology and treatment of these syndromes. Despite their impressive experience in the operative management of neurovascular compression syndromes, the authors do not give clearly defined directives for their choice of procedures to their surgical readers.

The inclusion of some detail case notes and of summaries of case histories of 51 patients adds to the value of the monograph. The book is excellently produced and its value is enhanced by the clear illustrations. It is undoubtedly a worthy addition to the series of Modern Surgical Monographs.

\section{Control of Immunogenesis by the Nervous System}

Editor: A. N. GoRdienko, Rostov-on-Don, 1958. Translation from the Russian by A. Hofman, M. Paenson, Z. S. Cole and M. Weiner. Pp. I8r + vi, illustrated. Published by Israel Program for Scientific Translations and National Science Foundation, Washington D.C. 1961. 60s.

Professor Gordienko is a physician who believes that the production of antibodies is always mediated through the nervous system and that direct contact of antigen with the plasma cells which produce antibodies is unnecessary. This book includes accounts of long series of experiments which he has performed to support his theory. Many of these are extremely ingenious and obviously require a very refined technique. In one, for example, he isolated the carotid sinus from all its vascular connections and injected into it an antigen containing no less than a millicurie of ${ }^{32} \mathrm{P}$, removing the whole structure two or three minutes later without allowing any of the radioactive phosphate to escape into the general circulation.

This then is an account of a very unorthodox hypothesis and of an experimental basis for it. Such a radical departure from present-day beliefs is difficult to accept, and it would be very desirable for some of these critical experiments to be repeated in other laboratories. However, I understand that even in Russia, Professor Gordienko's views are regarded with a certain reserve.

Some of the experimental data are given in insufficient detail for the load which they are made to carry and there are some sections, particularly near the end of the book, which appear quite unrelated to its general out- line, and to convey little information of scientific value. One gets the impression that Professor Gordienko is an enthusiast for his hypothesis; this book is not suff ciently detailed to allow one to decide whether has enthusiasm is justified, and one cannot but incline to the view that he is deceiving himself; but this lack of faith is certainly in part due to prejudice, and it would be desirable for someone to repeat some of his criticgl experiments.

Allowing for the difficulties of translating a high inflected language into one much less inflected, th book is surprisingly easy to read.

\section{Rehabilitation of Hand Function}

A. N. Leont'ev; A. V. ZAPorozheK. Translated from the Russian by B. HaIGH, M.A., M.B., B.CHIR. and edited by W. Ritchie Russell, C.B.E., M. D.SC., F.R.C.P. Pp. xviii + 199, illustrated. Oxforh, London, New York and Paris: Pergamon Press 1960. 6os.

This small volume has emanated from the Moscow State University. The unusual method of reproduef tion needs mastering before the reader can get a tripe understanding of the text, which describes experiment evidence of the psychological basis of upper limb dyifunction, and methods of rehabilitation evolved कs result of these experiments. The essential message is that rehabilitation exercises must have a purpose or the patient loses interest. The Russians had a vast number of upper limb injuries during the war, many of whornt were inadequately treated initially, and they conf menced their rehabilitation with multiple stiff joints, the end-results being functionally useful limbs. The authors have realized that rehabilitation of the hand essentially that of the upper limb as a whole, and apart from the post-operative recovery of a Kruken hand there appears to be no part of the book specen fically corresponding to the title.

This is an interesting monograph which is wh worth reading by those who do not yet believe in the functional result, but even with the line drawings and the ex-gratia payment of royalties by the publishers the Russian authors the price seems hard to justify.

\section{Surgery and Clinical Pathology in the Tropics}

Charl.ps IBowesman, O.B.E., B.A., M.D., F.R.C.s. Pp. viii + ro68, illustrated. Edinburgh and London: E. \& S. Livingstone Ltd. 1960. £5 1영

The doctor working in the tropics, often assisted onty by a small nursing staff, may be confronted with bewildering variety of pathological conditions and neegd to assume the functions of surgeon, obstetriciab, parasitologist and anæsthetist.

Mr. Bowesman writes with the authority of one who is familiar with the difficulties which beset the single handed practitioner in an underdeveloped communit 7 and his enormous experience is set down in th: excellently illustrated and extensively documented boos

After general chapters on nutrition, malaria and sickle cell disease in relation to surgery, the entire field of surgery and obstetrics under tropical conditions is dealt with. The subject matter ranges from crocodifo bites to portal hypertension and from native eneme injuries to Siamese twins.

The author in his introduction claims to have ma\&e most of the mistakes which most juniors make. He hi succeeded in producing a book which, constantly bearing in mind the requirements of the surgeon without tropicad experience, will help to avoid many pitfalls and provide sound advice in most surgical situations likely to encountered. 